\title{
Spermatogenesis and cryptorchidism
}

\section{Giovanni Cobellis ${ }^{1}$, Carmine Noviello ${ }^{1}$, Fabiano Nino ${ }^{1}$, Mercedes Romano ${ }^{1}$, Francesca Mariscoli ${ }^{1}$, Ascanio Martino ${ }^{1}$, Pio Parmeggiani ${ }^{2}$ and Alfonso Papparella ${ }^{2}$}

1 Paediatric Surgery, Salesi Children's Hospital, Università Politecnica delle Marche, Ancona, Italy

2 Paediatric Surgery, Department of Paediatrics, Faculty of Medicine, Second University of Naples, Naples, Italy

\section{Edited by:}

Riccardo Pierantoni, Second

University of Naples, Italy

Reviewed by:

Rosaria Meccariello, University of

Naples Parthenope, Italy

Paola Piomboni, University of Siena, Italy

\section{*Correspondence:}

Giovanni Cobellis, Paediatric Surgery,

Salesi Children's Hospital, Università

Politecnica delle Marche, Via

Corridoni, Ancona 11, Italy

e-mail:g.cobellis@univpm.it
Cryptorchidism represents the most common endocrine disease in boys, with infertility more frequently observed in bilateral forms. It is also known that undescended testes, if untreated, lead to an increased risk of testicular tumors, usually seminomas, arising from mutant germ cells. In normal testes, germ cell development is an active process starting in the first months of life when the neonatal gonocytes transform into adult dark (AD) spermatogonia. These cells are now thought to be the stem cells useful to support spermatogenesis. Several researches suggest that AD spermatogonia form between 3 and 9 months of age. Not all the neonatal gonocytes transform into AD spermatogonia; indeed, the residual gonocytes undergo involution by apoptosis. In the undescended testes, these transformations are inhibited leading to a deficient pool of stem cells for post pubertal spermatogenesis. Early surgical intervention in infancy may allow the normal development of stem cells for spermatogenesis. Moreover, it is very interesting to note that intra-tubular carcinoma in situ in the second and third decades have enzymatic markers similar to neonatal gonocytes suggesting that these cells fail transformation into AD spermatogonia and likely generate testicular cancer (TC) in cryptorchid men. Orchidopexy between 6 and 12 months of age is recommended to maximize the future fertility potential and decrease the TC risk in adulthood.

Keywords: cryptorchidism, undescended testes, spermatogenesis, germ cells, testicular cancer, orchidopexy

\section{INTRODUCTION}

Undescended testis or cryptorchidism is the most common genital abnormality in boys. The prevalence of cryptorchidism in full-term newborns range between 1 and $3 \%$, reaching $30 \%$ in prematures $(1-3)$. The pathology is bilateral in about $20 \%$ of the cases. About $80 \%$ of undescended testes are palpable and $20 \%$ are non-palpable (3-5). Palpable undescended testes are located along the inguino-scrotal region. Non-palpable testes may fall into one of the following categories: intra-abdominal location, agenesis, intrauterine demise, or inguinal location caused by dysplasia or atrophy. It is important to differentiate the true cryptorchidism from the retractile testis, which is a normal finding and usually it does not require surgical treatment. Acquired cryptorchidism has been observed when the retractile testis ascent in the inguinal canal during the infancy (ascending testis).

The main risk factors for the cryptorchid testis are infertility and testicular cancer (TC).

The risk of infertility in adulthood is more significant in patients with bilateral undescended testes (6). Approximately $10 \%$ of the infertile men have a history of cryptorchidism and orchidopexy (7). Azoospermia is evident in $13 \%$ of unilateral cryptorchidism and increase to $89 \%$ in untreated bilateral cryptorchid patients (8), although boys with one undescended testis have a lower fertility rate, they have the same paternity rate as boys with bilateral descended testes. Boys with bilateral undescended testes have a lower fertility and a paternity rate (9). In some studies, patients with unilateral cryptorchidism had normal spermatogenesis, suggesting that additive detrimental factors may be responsible for impaired fertility. The studied mechanisms of the infertility in cryptorchidism are multiple (7). The hyperthermia, between 35 and $37^{\circ} \mathrm{C}$ rather than $33^{\circ} \mathrm{C}$, evoked by the abnormal position of the testis may respond for the impaired spermatogenesis. Anatomical congenital anomalies associated to undescended testis as testis-epididymis disjunction or iatrogenic lesions of vas and testis during orchidopexy may also contribute to infertility. Retrospective studies in infertile patients with history of cryptorchidism have demonstrated an increased incidence of anti-sperm antibodies which is more evident in pubertal age (1, 8). Sinisi et al. showed that cryptorchidism may elicit an autoimmune response against sperm antigens in childhood independent of testis location and orchidopexy (1).

It is known that undescended testes, if untreated, lead to an increased risk of TC, usually seminomas (10), arising from mutant germ cells. TC is a solid neoplasm that has an incidence of $1 \%$ of all cancers in men and is the most common between 20 and 30 years of life $(11,12)$. Boys with an undescended testis have a 20 -fold higher risk to develop a TC and about $10 \%$ of the cases of TC develop in men with a history of cryptorchidism (13).

In this review, we focus on the current knowledge about the abnormal germ cell development in the undescended testes and its possible relationship with the impaired spermatogenesis and TC in adulthood. In the second section of this review, we discuss the treatment of cryptorchidism and the possible role of the early orchidopexy in the prevention of both infertility and cancer. 


\section{GERM CELL DEVELOPMENT, INFERTILITY, AND TESTICULAR} CANCER IN CRYPTORCHIDISM

The germ cell development and its modification in cryptorchidism have been recently matter of many researches $(2,14,15)$.

Spermatogenesis is the process by which sperm cells are produced. In men, it starts at puberty, resulting from the increased levels of gonadotropins and testosterone. It is a complex process including sequential steps of mitosis, meiosis, and differentiation. In each of these steps, endocrine, paracrine, and autocrine factors are involved (16). Spermatogenesis takes place in the seminiferous tubule: here germ cells are organized from the base of the tubule to the lumen and progressively develop from spermatogonia to spermatids. In the last step, spermatids differentiate through morphological transformation into spermatozoa (spermiogenesis) (17) which are finally released from the Sertoli cells into the lumen of the seminiferous tubule (spermiation).

However, germ cell development is an active process. It starts during the first years after birth when neonatal gonocytes change into adult dark $(\mathrm{AD})$ spermatogonia. These are stem cells and have a dark nucleus that specifically characterize them from the other germ cells. Therefore, AD spermatogonia do not directly take part to sperm production; nevertheless, they ensure a supply of stem cells for spermatogenesis. Indeed, AD spermatogonia replicate to produce adult pale (AP) spermatogonia, with light nuclei. These cells produce by mitosis the type B spermatogonia which further divide and differentiate into primary spermatocytes which are already evident in the testes of children 4 years of age $(2,18)$. Two sequential meiotic divisions and spermiogenesis lead to final development of round spermatids and spermatozoa, respectively (19).

Several data suggest that AD spermatogonia form between 3 and 9 months of age. This developmental cycle needs normal testicular hormones and the optimal scrotal temperature of $33^{\circ} \mathrm{C}$ $(20,21)$. The hormonal regulation of these changes is not fully understood, with evidence for a possible role of gonadotropins and androgens. Not all the neonatal gonocytes transform into $\mathrm{AD}$ spermatogonia. The remaining gonocytes undergo involution by apoptosis. Genetic aberrations and environmental conditions influence these processes.

The failure of transformation of gonocytes into $\mathrm{AD}$ spermatogonia may produce infertility in boys.

Hadziselimovic and Herzog (15) have demonstrated that the process of transformation of neonatal gonocytes into $\mathrm{AD}$ spermatogonia during the first year of life is crucial for male fertility. The inhibition of this process in undescended testis leads to a deficient pool of stem cells for post pubertal spermatogenesis and infertility. Moreover, in undescended testes, germ cells loss starts at 6 months of age. Testicular biopsies at time of orchidopexy confirmed the importance of $\mathrm{AD}$ spermatogonia for fertility in cryptorchid patients. Tasian and coworkers (22) observed greater germ cell depletion in abdominal testes compared with palpable testes and a progressive germ cell loss for each month the testes remain undescended.

It is very interesting to note that the intra-tubular carcinoma in situ (CIS) in the second and third decade has enzyme markers similar to neonatal gonocytes as placental alkaline phosphatase expression, suggesting that these cells, that fail to develop in $\mathrm{AD}$ spermatogonia at 3-9 months of age, are the origin of cancer in cryptorchid men (23). Studies have suggested that the precursor cells of testis cancer, testicular CIS, are similar to fetal gonocytes. A current hypothesis (2) is that, due to the high temperature anomaly of undescended testis, an abnormal apoptosis allows some gonocytes to persist and become CIS with progressive mutation and/or cellular unbalance, and eventually malignancy in adulthood. These abnormal gonocytes are kept in a defined environment "suspended animation" in the germ-line and, due to the accumulation of mutations, may undergo transformation becoming the source of the CIS $(2,21,24)$.

The etiology accepted for germ cell carcinoma remains unknown, although disturbances in the microenvironment provided by the Sertoli and Leydig cells may play an important role. In fact, spermatogenesis is strictly controlled and depends on a succession of signals supplied from the local environment $(11,25,26)$ and Leydig cells, next to their steroidogenic function, during development express the insulin-like-3 gene (INSL3), which is responsible for gubernaculum maturation and testicular descent (27). A specific association of mutations in INSL3 with cryptorchidism has been described but its possible role in TC development and infertility needs to be clarified (28).

Olesen et al. linked the development of TC not only with cryptorchidism but also with other urogenital anomalies such as hypospadia (29). In fact, epidemiological studies in males who presented fertility problems tend to lean toward an enhanced risk of testicular germ cell tumor (30). The development of TC is associated with many chromosomal abnormalities and this raises the problem for close monitoring of these patients. Kanetsky et al. (31) demonstrated common genetic variants associated to an increased risk of testicular germ cell cancer (TGCC) and found that seven markers at 12p22 within KITLG (c-KIT ligand) reached genome-wide significance. This gene has been involved in several aspects of primordial germ cell development, migration, and survival (32).

Concerning the development of the urogenital sinus and particularly the testis, the impacts of endocrine disruptors have been fairly well described on human and experimental models (33-35). This is especially true for hypospadia, cryptorchidism, and infertility; but the link with TGCC has to be explained. The unbalanced equilibrium between the estrogen and androgen levels in utero is hypothesized to influence the risk of TC. Thus, mutations in testosterone gene expression may change the level of testosterone in vivo and hypothetically the risk of developing TC (36).

As discussed before, hormonal regulation is very significant in the development of the germ-line. Beside the importance of fetal development, it seems that puberty should be an important moment, when hormone levels reach optimal concentrations for the secondary sex characters development. It has been shown that sperm agglutinating antibodies appear in young boys with cryptorchidism and they are more prevalent during puberty (1). This also coincides with the appearance of TGCC, as men affected are between 15 and 35 years old, suggesting that puberty and probably the increase in hormone concentrations should be central issues (37). 


\section{HORMONAL AND SURGICAL TREATMENT OF CRYPTORCHIDISM}

The goals of treatment of cryptorchidism are mainly two: preserve fertility and reduce the risk of neoplastic disease. Last but not the least, treatment allows the testicular self-examination for an early diagnosis and detection of TC.

Hormonal treatment with human chorionic gonadotropin (hCG) or gonadotropin-releasing hormone (GnRH) may be initially administered for cryptorchidism because it should promote the testicular descent (38). The theoretical basis for its use is to stimulate the Leydig cells to produce testosterone, inducing inguinal-scrotal testicular descent. Potential harmful effects of hormonal treatment on the developing testes, including apoptosis, inflammation, and reduced number of germ cells are still under study. In addition, there are reports which suggest that the hormonal stimulation in infancy may be damaging to the testes (39). It has been observed, in hCG-treated rats, a poor differentiation of the seminiferous epithelium, with high Leydig cell evidence and increased inter-tubular eosinophilic material (40). These experimental data emphasize the possible negative outcome of hormone therapy on germ cell line and its main action on Leydig cells. The increased synthesis of vascular endothelial growth factor (VEGF), determined by hCG therapy also highlights the increased cell permeability causing interstitial edema. The role of VEGF on spermatogenesis is unclear. Several findings have revealed several inhibitory effects of VEGF on spermatogenesis $(40,41)$.

Considering the poor efficacy and the possible adverse effects of hormonal therapy, surgery must be preferred (42).

Orchidopexy is the cornerstone of cryptorchidism treatment. Inguinal operation is the standard approach for palpable testis. Laparoscopy is the gold standard technique for both diagnosis and treatment of non-palpable testes (3-5). Early surgical treatment may preserve fertility. Orchidopexy is commonly performed before 2 years of age and increasing research suggest that surgery before 1 year of age may permit the normal spermatogenesis by preventing degenerative changes of the testes and germ cell loss $(22,43)$. However, early orchidopexy does not guarantee normal fertility in adulthood. Hadziselimovic showed that despite orchidopexy before 6 months of age, up to $35 \%$ of boys will grow up to be infertile regardless of the normal total germ cell count on testicular biopsies performed at the time of orchidopexy (44). The current practice for the acquired cryptorchidism is to operate at diagnosis, by a scrotal approach, although the prognosis seems to be better than congenital cryptorchidism considering the normal development and apoptosis of the germinal cells during the first year of life.

Since the link between cryptorchidism and TC seems to be an abnormal development of the primary germ-line, any attempt to normalize this process, as early surgery, will permit a normal growth of germ cells, thereby avoiding cancer as well as oligospermia or azoospermia. However, it should be mentioned that some studies failed to demonstrate a correlation between the time of surgery and cancer risk (45). A systematic review and meta-analysis of the literature by an American group has concluded that prepubertal orchiopexy may decrease the risk of malignancy and that early surgical intervention is indicated in children with cryptorchidism leading to a better growth of the testis (46).

\section{CONCLUSION}

Cryptorchidism is a risk factor for infertility and TC in adulthood. To date, orchidopexy is recommended between 6 and 12 months of age. The aim of an early surgical intervention is to prevent the abnormal germ cell development and ultimately decrease the risk of infertility and malignancy in adulthood.

\section{REFERENCES}

1. Sinisi A, Pasquali D, Papparella A, Valente A, Orio F, Esposito D, et al. Antisperm antibodies in cryptorchidism before and after surgery. J Urol (1998) 160:1834-7. doi:10.1016/S0022-5347(01)62428-5

2. Hutson JM. Undescended testis: the underlying mechanism and the effects on germ cells that cause infertility and cancer. J Pediatr Surg (2013) 48:903-8. doi:10.1016/j.jpedsurg.2013.02.001

3. Papparella A, Romano M, Noviello C, Cobellis G, Nino F, Del Monaco C, et al. The value of laparoscopy in the management of non-palpable testis. J Pediatr Urol (2010) 6:550-4. doi:10.1016/j.jpurol.2009.12.010

4. Papparella A, Parmeggiani P, Cobellis G, Mastroianni L, Stranieri G, Pappalepore $\mathrm{N}$, et al. Laparoscopic management of nonpalpable testes: a multicenter study of the Italian society of videosurgery in infancy. J Pediatr Surg (2005) 40:696-700. doi:10.1016/j.jpedsurg.2005.01.010

5. Papparella A, Zamparelli M, Cobellis G, Amici G, Saggiomo G, Parmeggiani P, et al. Laparoscopy for nonpalpable testis: is inguinal exploration always necessary when the cord structures enter the inguinal ring. Pediatr Endosurg Innov Tech (1999) 3:29-33. doi:10.1089/pei.1999.3.29

6. Chung E, Brock GB. Cryptorchidism and its impact on male fertility: a state of art review of current literature. Can Urol Assoc J (2011) 5(3):2010-4. doi:10.5489/cuaj.1010

7. Robin G, Boitrelle F, Marcelli F, Colin P, Leroy-Martin B, Mitchell V, et al. Cryptorchidism: from physiopathology to infertility. Gynecol Obstet Fertil (2010) 38(10):588-99. doi:10.1016/j.gyobfe.2010.08.015

8. Urry RL, Carrel DT, Starr NT, Snow BW, Middleton RG. The incidence of antisperm antibodies in infertility patients with a history of cryptorchidism. J Urol (1994) 151:381-3.

9. Tekgul S, Riedmiller H, Gerharz E, Hoebeke P, Kocvara R, Nijman R, et al. The Cryptorchidism: Guidelines on Pediatric Urology. Arnhem: European Association of Urology, European Society for Paediatric Urology (2009). p. 8-11.

10. Ferguson L, Agoulnik AI. Testicular cancer and cryptorchidism. Front Endocrinol (Lausanne) (2013) 4:32. doi:10.3389/fendo.2013.00032

11. Vega A, Baptissart M, Caira F, Brugnon F, Lobaccaro JMA, Volle DH. Epigenetic: a molecular link between testicular cancer and environmental exposures. Front Endocrinol (Lausanne) (2012) 3:150. doi:10.3389/fendo.2012.00150

12. Ziglioli F, Maestroni U, Dinale F, Ciuffreda M, Cortellini P. Carcinoma in situ (CIS) of the testis. Acta Biomed (2011) 82(2):162-9.

13. Mannuel HD, Mitikiri N, Khan M, Hussain A. Testicular germ cell tumors: biology and clinical update. Curr Opin Oncol (2012) 24:266-71. doi:10.1097/CCO. 0b013e32835167fc

14. Hadziselimovic F, Hocht B, Herzog B, Buser MW. Infertility in cryptorchidism is linked to the stage of germ cell development at orchidopexy. Horm Res (2007) 68(1):46-52. doi:10.1159/000100874

15. Hadziselimovic F, Herzog B. The importance of both an early orchidopexy and germ cell maturation for fertility. Lancet (2001) 358:1156-7. doi:10.1016/S01406736(01)06274-2

16. Pierantoni R, Cobellis G, Meccariello R, Fasano S. Evolutionary aspects of cellular communication in the vertebrate hypothalamo-hypophysio-gonadal axis. Int Rev Cytol (2002) 218:69-141. doi:10.1016/S0074-7696(02)18012-0

17. Cacciola G, Chioccarelli T, Fasano S, Pierantoni R, Cobellis G. Estrogens and spermiogenesis: new insight from type 1 cannabinoid receptor knockout mice. Int J Endocrinol (2013) 2013:501350. doi:10.1155/2013/501350

18. Yuasa J, Ito H, Toyama Y, Yuasa S, Masai M. Postnatal development of the testis in Japanese children based on observations of undescended testes. Int J Urol (2001) 8(9):490-4. doi:10.1046/j.1442-2042.2001.00357.x

19. de Kretser DM, Loveland KL, Meinhardt A, Simorangkir D, Wreford N. Spermatogenesis. Hum Reprod (1998) 13(Suppl 1):1-8. doi:10.1093/humrep/13. suppl_1.1

20. Hadziselimovic F, Thommen L, Girard J. The significance of postnatal gonadotropin surge for testicular development in normal and cryptorchid testes. J Urol (1986) 136:274-6. 
21. Ong C, Hasthorpe S, Hutson JM. Germ cell development in the descended and cryptorchid testis and the effects of hormonal manipulation. Pediatr Surg Int (2005) 21:240-54. doi:10.1007/s00383-005-1382-0

22. Tasian GE, Hittelman AB, Kim GE, Disandro MJ, Baskin LS. Age at orchiopexy and testis palpability predict germ and Leydig cell loss: clinical predictors of adverse histological features of cryptorchidism. J Urol (2009) 182:704-9. doi:10.1016/j.juro.2009.04.032

23. Jørgensen N, Rajpert-De Meyts E, Graem N, Müller J, Giwercman A, Skakkebaek NE. Expression of immunohistochemical markers for testicular carcinoma in situ by normal human fetal germ cells. Lab Invest (1995) 72(2):223.

24. Hutson JM, Balic A, Nation T, Southwell B. Cryptorchidism. Semin Pediatr Surg (2010) 19:215-24. doi:10.1053/j.sempedsurg.2010.04.001

25. Skinner MK, Norton JN, Mullaney BP, Rosselli M, Whaley PD, Anthony CT Cell interactions and the regulation of testis function. Ann N Y Acad Sci (1991) 637:354-63. doi:10.1111/j.1749-6632.1991.tb27322.x

26. Verhoeven G. Local control systems within the testis. Baillieres Clin Endocrinol Metab (1992) 6:313-33. doi:10.1016/S0950-351X(05)80152-1

27. Ivell R, Anand-Ivell R. Biological role and clinical significance of insulin-like peptide 3. Curr Opin Endocrinol Diabetes Obes (2011) 18:210-6. doi:10.1097/ MED.0b013e3283453fe6

28. Ferlin A, Bogatcheva NV, Gianesello L, Pepe A, Vinanzi C, Agoulnik AI, et al. Insulin-like factor 3 gene mutations in testicular dysgenesis syndrome: clinical and functional characterization. Mol Hum Reprod (2006) 12:401-6. doi:10.1096/Molehr/gal043

29. Olesen IA, Sonne SB, Hoei-Hansen CE, Rajpert-De Meyts E, Skakkebaek NE. Environment, testicular dysgenesis and carcinoma in situ testis. Best Pract Res Clin Endocrinol Metab (2007) 21:462-78. doi:10.1016/j.beem.2007.04.002

30. Burns WR, Sabanegh E, Dada R, Rein B, Agarwal A. Is male infertility a forerunner to cancer? Int Braz J Urol (2010) 36:527-36. doi:10.1590/\$167755382010000500002

31. Kanetsky PA, Mitra N, Vardhanabhuti S, Li M, Vaughn DJ, Letrero R, et al. Common variation in KITLG and at5q31.3 predisposes to testicular germ cell cancer. Nat Genet (2009) 41:811-5. doi:10.1038/ng.393

32. Gu Y, Runyan C, Shoemaker A, Surani A, Wylie C. Steel factor controls primordial germ cell survival and motility from the time of their specification in the allantois, and provides a continuous niche throughout their migration. Development (2009) 136:1295-303. doi:10.1242/dev.030619

33. Volle DH, Decourteix M, Garo E, McNeilly J, Fenichel P, Auwerx J, et al. The orphan nuclear receptor small heterodimer partner mediates male infertility induced by diethylstilbestrol in mice. J Clin Invest (2009) 119:3752-64. doi:10.1172/JCI38521

34. Toppari J, Virtanen HE, Main KM, Skakkebaek NE. Cryptorchidism and hypospadias as a sign of testicular dysgenesis syndrome (TDS): environmental connection. Birth Defects Res A Clin Mol Teratol (2010) 88(10):910-9. doi:10.1002/bdra.20707

35. Desdoits-Lethimonier C, Albert O, Le Bizec B, Perdu E, Zalko D, Courant F, et al. Human testis steroidogenesis is inhibited by phthalates. Hum Reprod (2012) 27(5):1451-9. doi:10.1093/humrep/des069

36. Kristiansen W, Aschim EL, Andersen JM, Witczak O, Fosså SD, Haugen TB. Variations in testosterone pathway genes and susceptibility to testicular cancer in Norwegian men. Int J Androl (2012) 35(6):819-27. doi:10.1111/j.1365-2605. 2012.01297.x

37. Jacobsen GK, Henriques UV. A fetal testis with intratubular germ cell neoplasia (ITGCN). Mod Pathol (1992) 5:547-9.

38. Papparella A, Coppola S, Nino F, Andrade Barrientos M, Gasparini N. Epidemiology and treatment of cryptorchidism and retractile testis. Minerva Pediatr (2013) 65(1):77-82.

39. Cortes D, Thorup J, Visfeldt J. Hormonal treatment may harm the germ cells in 1 to 3-year-old boys with cryptorchidism. J Urol (2000) 163:1290-2. doi:10.1016/S0022-5347(05)67763-4

40. Papparella A, Nino F, Noviello C, Romano M, Papparella S, Paciello O, et al. Morphologic changes due to human chorionic gonadotropin in the rat testis: role of vascular endothelial growth factor. Open J Pediatr (2013) 3:85-91. doi:10.4236/ojped.2013.32016

41. Nalbandian A, Dettin L, Dym M, Ravindranath N. Expression of vascular endothelial growth factor receptors during male germ cell differentiation in the mouse. Biol Reprod (2003) 69:985-94. doi:10.1095/biolreprod.102.013581

42. Ritzèn EM. Undescended testes: a consensus on management. Eur J Endocrinol (2008) 159:S87-90. doi:10.1530/EJE-08-0181

43. Feyles F, Peiretti V, Mussa A, Manenti M, Canavese F, Cortese MG, et al. Improved sperm count and motility in young men surgically treated for cryptorchidism in the first year of life. Eur J Pediatr Surg (2013). doi:10.1055/s-0033-1349715

44. Hadziselimovic F. Early successful orchidopexy does not prevent from developing azoospermia. Int Braz J Urol (2007) 32(5):570-3. doi:10.1590/S167755382006000500012

45. Hack WW, Sijstermans K, Van Der Voort-Doedens LM. Correction of cryptorchidism and testicular cancer. N Engl J Med (2007) 357:825-7. doi:10.1056/ NEJMc071510

46. Walsh TJ, Dall'Era MA, Croughan MS, Carroll PR, Turek PJ. Prepubertal orchiopexy for cryptorchidism may be associated with lower risk of testicular cancer. J Urol (2007) 178(Pt 1):1440-6. doi:10.1016/j.juro.2007.05.166

Conflict of Interest Statement: The authors declare that the research was conducted in the absence of any commercial or financial relationships that could be construed as a potential conflict of interest.

Received: 30 January 2014; paper pending published: 10 February 2014; accepted: 14 April 2014; published online: 01 May 2014.

Citation: Cobellis G, Noviello C, Nino F, Romano M, Mariscoli F, Martino A Parmeggiani P and Papparella A (2014) Spermatogenesis and cryptorchidism. Front. Endocrinol. 5:63. doi: 10.3389/fendo.2014.00063

This article was submitted to Experimental Endocrinology, a section of the journal Frontiers in Endocrinology.

Copyright (c) 2014 Cobellis, Noviello, Nino, Romano, Mariscoli, Martino, Parmeggiani and Papparella. This is an open-access article distributed under the terms of the Creative Commons Attribution License (CC BY). The use, distribution or reproduction in other forums is permitted, provided the original author(s) or licensor are credited and that the original publication in this journal is cited, in accordance with accepted academic practice. No use, distribution or reproduction is permitted which does not comply with these terms. 